\title{
Identification of a mesoscale model with multiscale experimental observations
}

\author{
M.T. Nguyen, C. Desceliers and C. Soize
}

\begin{abstract}
This paper deals with a multiscale statistical inverse method for performing the experimental identification of the elastic properties of materials at macroscale and at mesoscale within the framework of a heterogeneous microstructure which is modeled by a random elastic media. New methods are required for carrying out such multiscale identification using experimental measurements of the displacement fields at macroscale and at mesoscale performed with only a single specimen submitted to a given external load at macroscale. In this paper, for a heterogeneous microstructure, a new identification method is presented and is formulated within the framework of the three dimensional linear elasticity. It permits the identification of the effective elasticity tensor at macroscale and the identification of the stochastic tensor field modeling the apparent elasticity at the mesoscale. A validation is presented with experimental measurements simulated with a numerical model with a 2D plane stresses hypothesis.
\end{abstract}

M.T. Nguyen

Université Paris-Est, Laboratoire Modélisation et Simulation Multi-Echelle, MSME UMR 8208 CNRS, 5 bd Descartes, 77454 Marne-La-Vallée, Cedex 2, France.

C. Desceliers

Université Paris-Est, Laboratoire Modélisation et Simulation Multi-Echelle, MSME UMR 8208 CNRS, 5 bd Descartes, 77454 Marne-La-Vallée, Cedex 2, France. e-mail: christophe.desceliers@univ-paris-est.fr

C. Soize

Université Paris-Est, Laboratoire Modélisation et Simulation Multi-Echelle, MSME UMR 8208 CNRS, 5 bd Descartes, 77454 Marne-La-Vallée, Cedex 2, France. e-mail: christian.soize@ univparis-est.fr 


\section{Introduction}

The inverse methods for the experimental identification of the elastic properties of materials at the macroscale and/or mesoscale have been extensively studied. The experimental identification of microstructural morphology by image analysis began in the 1980s (see for instance [35, 36, 37]) and it has led to significant advances in the identification of mechanical properties (see, for instance $[2,3,4,7,8,9,10,11,12,13,16,22,23,24,30,31,32,33,34,40,41,42,43,44]$. Concerning the identification of stochastic models, the methodologies for statistical inverse problems in finite and infinite dimension are numerous and have given rise to numerous studies and publications. These methods make extensive use of the formulations and the tools of the functional analysis of boundary value problems as well as those of probability theory, including mathematical statistics (finite and infinite dimensional cases). Concerning the mathematical statistics, one can refer to $[39,45]$ and $[15,38,52,50]$ for the general principles on the statistical inverse problems. Early work on the statistical inverse identification of stochastic fields for random elastic media, using partial and limited experimental data, have primarily be devoted to the identification of statistical parameters of prior stochastic models (such as the spatial correlation scales and the level of statistical fluctuations) $[1,17,18,19,20,29,48,51]$. Those probabilistic/statistical methods are able to solve the statistical inverse problems related to the identification of prior stochastic models for the apparent elastic fields at mesoscale. Nevertheless, such experimental identification, which is carried out using measurements on a single specimen submitted to a given external load at macroscale and using measurements of the displacement fields at macroscale and mesoscale, requires new methods for identifying the statistical mean value of the random apparent elasticity tensor and the other parameters controlling its prior stochastic model as, for instance, the spatial correlation lengths and the parameters allowing the statistical fluctuations of the stochastic field to be controlled.

In this paper, a new identification method is presented. A statistical inverse multiscale method is formulated for a heterogeneous microstructure within the framework of the three-dimensional linear elasticity. This method permits both the identification of the effective elasticity tensor at macroscale and the identification of the stochastic tensor field which modelizes the apparent elasticity field at mesoscale. It is assumed that the experimental measurements of the displacement field are available at macroscale and at mesoscale. The prior stochastic model is a non-Gaussian tensor-valued random field adapted to the properties of the 3D-elasticity field and to the corresponding stochastic elliptic boundary value problem. The parameters of the prior stochastic model of the apparent elasticity random field at mesoscale, are its statistical mean value, its spatial correlation lengths and its level of statistical fluctuations. This identification of the stochastic model at mesoscale requires the knowledge of the effective elasticity tensor of macroscale and measurements of the displacements field at the two scales simultaneously for one given specimen submitted to a given static external loads. Thus, the proposed method is new. The theory 
will be presented for the 3D case and a numerical validation will be presented for the 2D plane stress in the framework of experimental measurements obtained by optical measurements (but, in the present paper, the validation will be performed with simulated experiments).

\section{Multiscale experimental configuration}

The specimen (whose microstructure is complex and heterogeneous at microscale) occupies a bounded macroscopic domain $\Omega^{\text {macro }}$ in $\mathbb{R}^{3}$. Surface forces, $\mathbf{f}^{\text {macro }}$, are applied on a part $\Sigma^{\text {macro }}$ of the boundary $\partial \Omega^{\text {macro }}$ of $\Omega^{\text {macro }}$. The other part $\Gamma^{\text {macro }}$ of $\partial \Omega^{\text {macro }}$ is fixed such that there is no rigid body displacement. At macroscale on $\Omega^{\text {macro }}$, the measured displacement field is denoted as $\mathbf{u}_{\mathrm{exp}}^{\text {macro }}$ and its associated strain tensor is denoted as $\varepsilon_{\exp }^{\text {macro }}$.

Let $\Omega^{\text {meso }}$ be a subdomain of the specimen at mesoscale (a REV) and let $\partial \Omega^{\text {meso }}$ be the boundary of $\Omega^{\text {meso }}$. Let $\mathbf{u}_{\exp }^{\text {meso }}$ be the experimental measurement on $\Omega^{\text {meso }}$ of the displacement field at mesoscale. The associated strain tensor is denoted as $\mathbb{E}_{\exp }^{\text {meso }}$. It is assumed that the experimental measurements of $\mathbf{u}_{\exp }^{\text {meso }}$ are obtained only for one subdomain $\Omega^{\text {meso }}$ related to one specimen. The volume average at mesoscale, $\mathbb{E}_{\exp }^{\text {meso }}$, of $\mathbb{E}_{\exp }^{\text {meso }}$ is introduced such that

$$
\underline{\mathbb{E}}_{\exp }^{\text {meso }}=\frac{1}{\left|\Omega^{\text {meso }}\right|} \int_{\Omega^{\text {meso }}} \mathbb{E}_{\exp }^{\text {meso }}(\mathbf{x}) d \mathbf{x} .
$$

The statistical fluctuations level of the experimental linearized strain field at mesoscale around the volume average, $\mathbb{E}_{\exp }^{\text {meso }}$, is estimated by $\delta_{\exp }^{\text {meso }}$ which is defined as

$$
\delta_{\exp }^{\text {meso }}=\frac{\sqrt{V_{\exp }^{\text {meso }}}}{\left\|\underline{\mathscr{e x p}}_{\exp }^{\operatorname{meso}}\right\|_{F}},
$$

in which

$$
V_{\exp }^{\text {meso }}=\frac{1}{\left|\Omega^{\text {meso }}\right|} \int_{\Omega^{\text {meso }}}\left\|\mathscr{E}_{\exp }^{\text {meso }}(\mathbf{x})-\underline{\mathbb{E}}_{\exp }^{\text {meso }}\right\|_{F}^{2} d \mathbf{x}
$$

and where $\|T\|_{F}$ is the Frobenius norm such that, for any second-order tensor $T=$ $\left\{T_{i j}\right\}_{i j}$, one has

$$
\|T\|_{F}^{2}=\sum_{i=1}^{3} \sum_{j=1}^{3} T_{i j}^{2}
$$




\section{Multiscale statistical inverse problem}

At macroscale, a deterministic boundary value problem is introduced for a 3D linear elastic medium, which modelizes the specimen in its experimental configuration (geometry, surface forces and Dirichlet conditions). At macroscale, the constitutive equation involves a prior model for the elasticity tensor $C^{\text {macro }}(\mathbf{a})$ which is parameterized by a vector a. For the 3D anisotropic elasticity, a represents the 21 constants of the elasticity tensor. The boundary value problem is formulated in displacement and the solution is denoted as $\mathbf{u}^{\text {macro }}$ (deterministic macroscale displacement field). The linearized strain tensor associated with $\mathbf{u}^{\text {macro }}$ is denoted as $\varepsilon^{\text {macro }}$. Tensor $C^{\text {macro }}(\mathbf{a})$ is unknown and must experimentally be identified, which means that parameter a must be identified using the measurements of the displacement field at macroscale. Consequently, a first numerical indicator $\mathscr{I}_{1}(\mathbf{a})$ is introduced in order to quantify the distance between $\varepsilon_{\exp }^{\text {macro }}$ and $\varepsilon^{\text {macro }}$. For a fixed value of parameter $\mathbf{a}$, this indicator is defined by

$$
\mathscr{I}_{1}(\mathbf{a})=\left\|\mid \varepsilon_{\exp }^{\text {macro }}-\varepsilon^{\text {macro }}(\mathbf{a})\right\| \|^{2},
$$

in which

$$
\left\|\mid \varepsilon_{\exp }^{\text {macro }}-\varepsilon^{\text {macro }}(\mathbf{a})\right\|^{2}=\int_{\Omega^{\text {macro }}}\left\|\varepsilon_{\exp }^{\text {macro }}(\mathbf{x})-\varepsilon^{\text {macro }}(\mathbf{x} ; \mathbf{a})\right\|_{F}^{2} d \mathbf{x} .
$$

At mesoscale, two additional numerical indicators, $\mathscr{I}_{2}(\mathbf{b})$ and $\mathscr{I}_{3}(\mathbf{a}, \mathbf{b})$, are constructed to identify the parameters $\mathbf{b}$ involved in the prior stochastic model of the apparent elasticity random field $\mathbf{C}^{\text {meso }}(\mathbf{b})$ which is considered as the restriction to subdomain $\Omega^{\text {meso }}$ of a statistically homogeneous random field $\left\{\mathbf{C}^{\text {meso }}(\mathbf{x} ; \mathbf{b}), \mathbf{x} \in \mathbb{R}^{3}\right\}$.

Concerning the construction of the second numerical indicator $\mathscr{I}_{2}(\mathbf{b})$, a random boundary value problem is introduced for a 3D linear elastic random media occupying subdomain $\Omega^{\text {meso }}$ and for which the apparent elasticity random field is $\mathbf{C}^{\text {meso }}(\mathbf{b})$. This random boundary value problem is formulated in displacement and the solution is denoted as $\mathbf{U}^{\text {meso }}$ (displacement random field) with the Dirichlet condition $\mathbf{U}^{\text {meso }}=\mathbf{u}_{\mathrm{exp}}^{\text {meso }}$ on boundary $\partial \Omega^{\text {meso }}$. The random linearized strain tensor field associated with $\mathbf{U}^{\text {meso }}$ is denoted as $\mathbb{E}^{\text {meso }}$. For any given parameters $\mathbf{b}$, numerical indicator $\mathscr{I}_{2}(\mathbf{b})$ is defined as

$$
\mathscr{I}_{2}(\mathbf{b})=\int_{\Omega^{\text {meso }}}\left(\delta^{\text {meso }}(\mathbf{x} ; \mathbf{b})-\delta_{\exp }^{\text {meso }}\right)^{2} d \mathbf{x}
$$

in which

$$
\delta^{\text {meso }}(\mathbf{x} ; \mathbf{b})=\frac{\sqrt{V^{\text {meso }}(\mathbf{x} ; \mathbf{b})}}{\left\|\underline{\mathbb{E}}^{\text {meso }}(\mathbf{b})\right\|_{F}}
$$

where

$$
\underline{\mathbb{E}}^{\text {meso }}(\mathbf{b})=\frac{1}{\left|\Omega^{\text {meso }}\right|} \int_{\Omega^{\text {meso }}} \mathbb{E}^{\text {meso }}(\mathbf{x} ; \mathbf{b}) d \mathbf{x}
$$


and

$$
V^{\text {meso }}(\mathbf{x} ; \mathbf{b})=E\left\{\left\|\mathbb{E}^{\text {meso }}(\mathbf{x} ; \mathbf{b})-\underline{\mathbb{E}}^{\text {meso }}(\mathbf{b})\right\|_{F}^{2}\right\},
$$

It should be noted that, for all $\mathbf{b}, \underline{\mathbb{E}}^{\text {meso }}(\mathbf{b})=\mathbb{E}_{\exp }^{\text {meso }}$. The third numerical indicator $\mathscr{I}_{3}(\mathbf{a}, \mathbf{b})$ depends on $\mathbf{a}$ and $\mathbf{b}$ since this numerical indicator quantifies the distance between the elasticity tensor $C^{\text {macro }}(\mathbf{a})$ used in boundary value problem at macroscale and the effective tensor $\mathbf{C}^{\text {eff }}(\mathbf{b})$ calculated by homogenization of the stochastic model at mesoscale on the REV, which depends on $\mathbf{b}$ only. We then have

$$
\mathscr{I}_{3}(\mathbf{a}, \mathbf{b})=\left\|C^{\text {macro }}(\mathbf{a})-E\left\{\mathbf{C}^{\text {eff }}(\mathbf{b})\right\}\right\|_{F}^{2} .
$$

The identification of parameters $\mathbf{a}$ and $\mathbf{b}$ that describe the stochastic model of the apparent elasticity random field $\mathbf{C}^{\text {meso }}(\mathbf{b})$ at mesoscale is obtained by solving a multiobjective optimization problem for the three indicators $\mathscr{I}_{1}(\mathbf{a}), \mathscr{I}_{2}(\mathbf{b})$ and $\mathscr{I}_{3}(\mathbf{a}, \mathbf{b})$.

\section{Validation of the method in 2D plane stresses}

The validation is performed within the framework of the linear elasticity in 2D plane stresses. It should be noted that the two directions are observed when the displacement fields are measured at macroscale and at mesoscale with a camera.

\subsection{Prior stochastic model of the apparent elasticity random field in $2 D$ plane stresses}

At mesoscale, the prior stochastic model of the apparent elastic random field $\mathbf{C}^{\text {meso }}$ is indexed by subdomain $\Omega^{\text {meso }}$ which is assumed to be a REV. A representation of $\mathbf{C}^{\text {meso }}$ with a minimum of parameters and adapted to elliptic problems is used. Parametric stochastic models have been proposed for scalar-valued stochastic fields $[5,6,21,24]$ and for non-Gaussian tensor-valued stochastic fields in the framework of the heterogeneous anisotropic linear elasticity [14, 46, 47, 51], with important enhancements to take into account the material symmetry and the existence of elasticity bounds [25, 26, 27, 28]. Hereinafter, the stochastic model is based on [46].

In using the Voigt notation, the fourth-order elasticity tensor $\mathbf{C}^{\text {meso }}(\mathbf{x})$ can be represented by a $(6 \times 6)$ real matrix. The strain vector is then denoted as $\left(\varepsilon_{11}, \varepsilon_{22}, 2 \varepsilon_{12}\right.$, $\left.\varepsilon_{33}, 2 \varepsilon_{23}, 2 \varepsilon_{13}\right)$ and the associated stress vector is denoted as $\left(\sigma_{11}, \sigma_{22}, \sigma_{12}, \sigma_{33}\right.$, $\left.\sigma_{23}, \sigma_{13}\right)$. Such numbering of those vectors, which is not usual, has been chosen for the sake of simplicity in 2D plane stresses, for which the $(3 \times 3)$ compliance matrix $\left[\mathbf{S}^{2 D}(\mathbf{x})\right]$ corresponds to the first $(3 \times 3)$ block of the $(6 \times 6)$ compliance ma$\operatorname{trix}\left[\mathbf{S}^{\text {meso }}(\mathbf{x})\right]=\left[\mathbf{C}^{\text {meso }}(\mathbf{x})\right]^{-1}$. 
The prior stochastic model of $\mathbf{C}^{\text {meso }}$ is then constructed in choosing $\left[\mathbf{S}^{\text {meso }}\right]=$ $\left\{\left[\mathbf{S}^{\text {meso }}(\mathbf{x})\right], \mathbf{x} \in \Omega^{\text {meso }}\right\}$ in the set $\mathrm{SFE}^{+}[46,49]$ of non-Gaussian second-order stochastic fields with values in the set of all the positive-definite symmetric $(6 \times 6)$ real matrices, for which the mean value is a given matrix $\left[\underline{S}^{\text {meso }}\right]=E\left\{\left[\mathbf{S}^{\text {meso }}(\mathbf{x})\right]\right\}$ for all $\mathbf{x}$ in $\Omega^{\text {meso }}$. As a result, the matrix-valued random field $\left\{\left[\mathbf{S}^{\text {meso }}(\mathbf{x})\right], \mathbf{x} \in \Omega^{\text {meso }}\right\}$ is described as a function of the entries of matrix $\left[\underline{S}^{\text {meso }}\right]$, of three spatial correlation lengths $\ell_{1}, \ell_{2}, \ell_{3}$ and of one parameter $\delta$ which controls the level of dispersion.

In the case of 2D plane stresses, random matrix $\left[\mathbf{S}^{2 D}(\mathbf{x})\right]$ (the left upper $(3 \times 3)$ block matrix of $\left[\mathbf{S}^{\text {meso }}(\mathbf{x})\right]$ ) can be written as a function of the entries of matrix $\left[\underline{S}^{2 D}\right]$ (left upper $(3 \times 3)$ block matrix of $\left.\left[\underline{S}^{\text {meso }}\right]\right)$, one spatial correlation length $\ell=\ell_{1}=\ell_{2}$ and dispersion parameter $\delta$. The prior model of the apparent elasticity random field $\left[\mathbf{C}^{2 D}\right]=\left\{\left[\mathbf{C}^{2 D}(\mathbf{x})\right], \mathbf{x} \in \Omega^{\text {meso }}\right\}$ with values in the set of the $(3 \times 3)$ real matrices is then constructed, for all $\mathbf{x}$ in $\Omega^{\text {meso }}$, as the inverse of the random matrix $\left[\mathbf{S}^{2 D}(\mathbf{x})\right]$. We then have

$$
\left[\mathbf{C}^{2 D}(\mathbf{x})\right]=\left[\mathbf{S}^{2 D}(\mathbf{x})\right]^{-1} \quad, \quad \text { a.s. }
$$

Consequently, the parameter $\mathbf{b}$ of the prior stochastic model of the apparent elasticity random field $\left[\mathbf{C}^{2 D}(\mathbf{b})\right]$ are $\mathbf{b}=\left(\boldsymbol{\delta}, \ell\right.$, entries of $\left.\left[\underline{S}^{2 D}\right]\right)$. It should be noted that random fields $\left[\mathbf{C}^{2 D}(\mathbf{b})\right]$ and $\left[\mathbf{S}^{2 D}(\mathbf{b})\right]$ do not belong to the set $\mathrm{SFE}^{+}$of non-Gaussian second-order stochastic fields with values in the set of all the positive-definite symmetric $(3 \times 3)$ real matrices.

\subsection{Construction of a simulated "experimental" database}

To validate the methodology, "experimental" measurements at macroscale and at mesoscale are both simulated in using a computational model. The 2D domain $\Omega^{\text {macro }}$ in the plane $\left(O x_{1} x_{2}\right)$, is defined as a square whose dimensions are $h=$ $10^{-2} \mathrm{~m}$. At mesoscale, the material is heterogeneous, anisotropic and linear elastic. A line force directed along $-x_{2}$, with an intensity of $5 \times 10^{-2} \mathrm{~N} / \mathrm{m}$, is applied on the edge $x_{2}=h$. The edge $x_{2}=0$ is fixed. A 2D plane stress state is assumed. At mesoscale, the 2D apparent elasticity field is constructed as a realization of the prior stochastic model of $\left[\mathbf{C}^{2 D}(\mathbf{b})\right]$ with $\ell=1.25 \times 10^{-4} \mathrm{~m}, \delta=0.4$ and where the entries of $\left[\underline{S}^{2 D}\right]$ are defined below. It is assumed that the elastic medium is transverse isotropic which yields

$$
\left[\underline{S}^{\text {meso }}\right]=\left(\begin{array}{cccccc}
\frac{1}{E_{T}} & -\frac{v_{T}}{E_{T}} & 0 & -\frac{v_{L}}{E_{L}} & 0 & 0 \\
-\frac{v_{T}}{E_{T}} & \frac{1}{E_{T}} & 0 & 0 & 0 & 0 \\
0 & 0 & \frac{2\left(1+v_{T}\right)}{E_{T}} & 0 & 0 & 0 \\
-\frac{v_{L}}{E_{L}} & -\frac{v_{L}}{E_{L}} & 0 & \frac{1}{E_{L}} & 0 & 0 \\
0 & 0 & 0 & 0 & \frac{1}{G_{L}} & 0 \\
0 & 0 & 0 & 0 & 0 & \frac{1}{G_{L}}
\end{array}\right)
$$


where $E_{L}=15.8 \times 10^{9} \mathrm{~Pa}, E_{T}=9.9 \times 10^{9} \mathrm{~Pa}, G_{L}=5.2 \times 10^{9} \mathrm{~Pa}, v_{L}=0.31$ et $v_{T}=$ 0.38 . Consequently, we have

$$
\left[\underline{S}^{2 D}\right]=\left(\begin{array}{ccc}
\frac{1}{E_{T}} & -\frac{v_{T}}{E_{T}} & 0 \\
-\frac{v_{T}}{E_{T}} & \frac{1}{E_{T}} & 0 \\
0 & 0 & \frac{2\left(1+v_{T}\right)}{E_{T}}
\end{array}\right) .
$$

Consequently, the vector $\mathbf{b}$ of parameters is then written as $\mathbf{b}=\left(\delta, \ell, E_{T}, v_{T}\right)$. At mesoscale, the realization of the apparent elasticity random field is simulated on the whole domain $\Omega^{\text {macro }}$.

A computational model is constructed with the finite element method and a regular finite element mesh with one million quadrangle elements (1,000 along $x_{1}$ and 1,000 along $x_{2}$, see Fig. 1, left). The strain field is numerically simulated in using a finite element interpolation in a regular grid of nodes with a mesoscale resolution on the whole domain $\Omega^{\text {macro }}$ (see Fig. 1, center). Measurements of the strain field $\varepsilon_{\exp }^{\text {macro }}$ is simulated at macroscale in extracting the values of the displacement field in a regular grid of $10 \times 10$ nodes and in using a finite element interpolation (see Fig. 1, upper right). In addition, in the subdomain defined as a square with dimension $10^{-3} \mathrm{~m}$ (mesoscale), the measurements of the strain field $\varepsilon_{\exp }^{\text {meso }}$ are simulated at mesoscale in extracting the values of the displacement field in a regular grid of $100 \times 100$ nodes and in using a finite element interpolation (see Fig. 1, lower right).

Figure 2 shows the values of $\left\{\varepsilon_{\exp }^{\text {macro }}\right\}_{22}$ for the simulated experimental strain field at macroscale with a resolution $10 \times 10$. The square in black dashed line represents the considered mesoscale subdomain. Figure 3 shows the values of $\left\{\varepsilon_{\exp }^{\operatorname{meso}}\right\}_{22}$ for the simulated experimental strain field at mesoscale with a resolution $100 \times 100$.

\subsection{Multi-objective optimization problem}

The identification of parameter $\mathbf{b}$ is carried out in searching for the optimal values $\mathbf{a}^{\text {macro }}$ and $\mathbf{b}^{\text {meso }}$ which solve the following multi-objective minimization problem

$$
\left(\mathbf{a}^{\text {macro }}, \mathbf{b}^{\text {meso }}\right)=\underset{\mathbf{a} \in \mathscr{A}^{\text {macro }}, \mathbf{b} \in \mathscr{B} \text { meso }}{\arg \min } \mathscr{I}(\mathbf{a}, \mathbf{b}),
$$

where $\mathscr{A}^{\text {macro }}$ and $\mathscr{B}^{\text {meso }}$ are the sets of the admissible values for $\mathbf{a}$ and $\mathbf{b}$, and where the components $\mathscr{I}_{1}(\mathbf{a}), \mathscr{I}_{2}(\mathbf{b})$ and $\mathscr{I}_{3}(\mathbf{a}, \mathbf{b})$ of vector $\mathscr{I}(\mathbf{a}, \mathbf{b})$ are defined by Eqs. (5), (7) et (11).

The multi-objective optimization problem defined by Eq. (15) is solved in using a genetic algorithm with an initial population size of 50. Less than 100 generations has been enough for constructing the Pareto front which is iteratively constructed, 


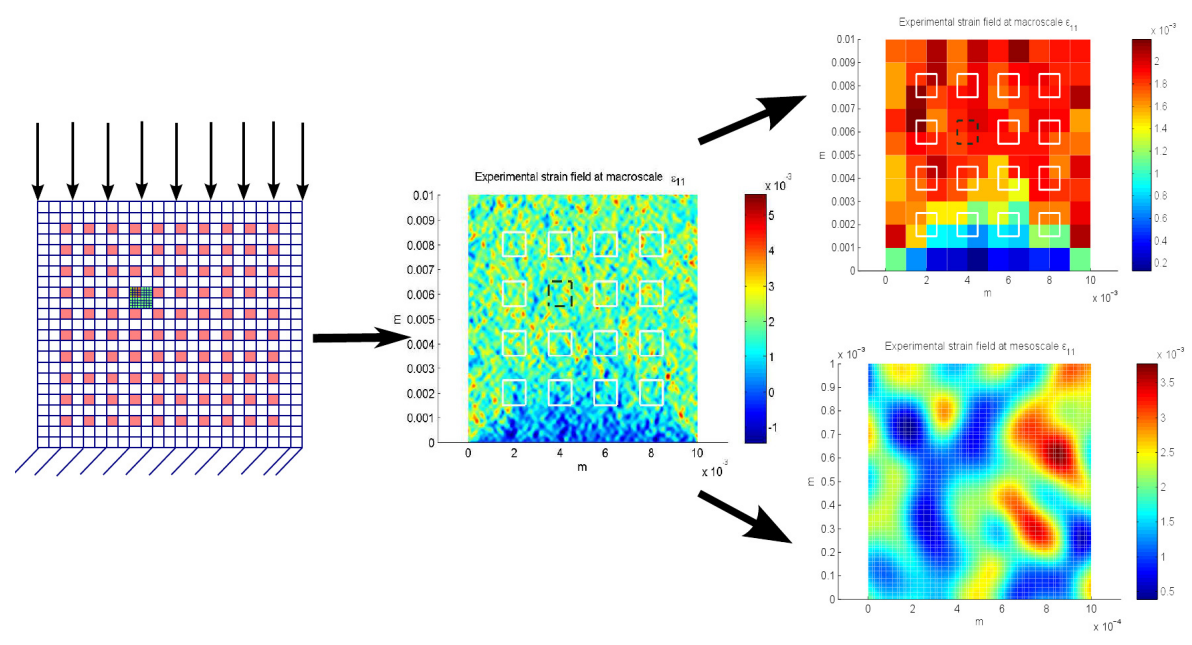

Fig. 1 Description of the methodology for the construction of the simulated experimental measurements in using the finite element method at macroscale and at mesoscale: FE model of the specimen at macroscale with a mesoscale resolution (left), component $\{11\}$ of the strain field at macroscale with a mesoscale resolution (center), component $\{11\}$ of the strain field at macroscale with a macroscale resolution (upper right) and component $\{11\}$ of the strain field at mesoscale with a mesoscale resolution (lower right).

at each generation of the genetic algorithm. The initial value of parameter a has been set to $\mathbf{a}^{(0)}$ and corresponds to the solution of the following partial optimization problem: $\mathbf{a}^{(0)}=\arg \min \mathscr{I}_{1}(\mathbf{a})$ for $\mathbf{a} \in \mathscr{A}^{\text {macro }}$, which is solved with the simplex algorithm. Actually, the value of $\mathbf{a}^{\text {macro }}$ is almost unchanged through the iterations when the multi-objective problem is solved. The optimal value $\mathbf{b}^{\text {meso }}$ is chosen as the point on the Pareto front that minimizes the distance between the Pareto front and the origin.

\subsection{Numerical results and validation}

At macroscale, the prior model of the material is chosen as a transverse isotropic model. Consequently, in 2D plane stress, parameter $\mathbf{a}=\left(E_{T}^{\text {macro }}, v_{T}^{\text {macro }}\right)$ is made up of the transverse Young modulus and the transverse Poisson coefficient. The optimal 


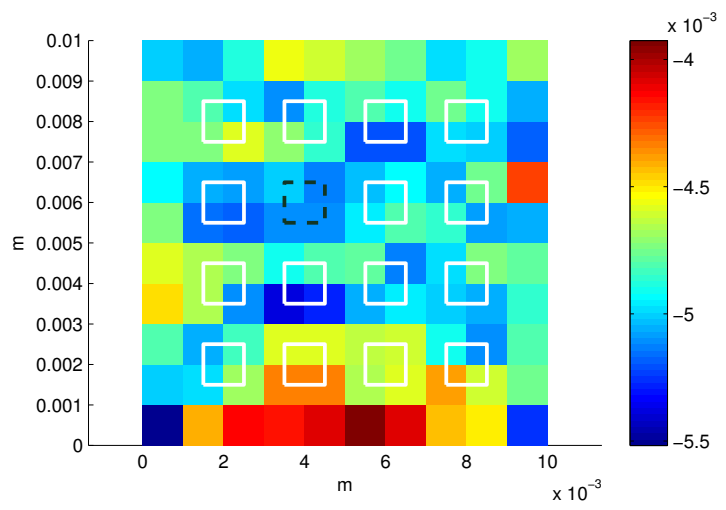

Fig. 2 Component $\left\{\varepsilon_{\exp }^{\text {macro }}\right\}_{22}$ of the simulated experimental strain field at macroscale with a resolution $10 \times 10$

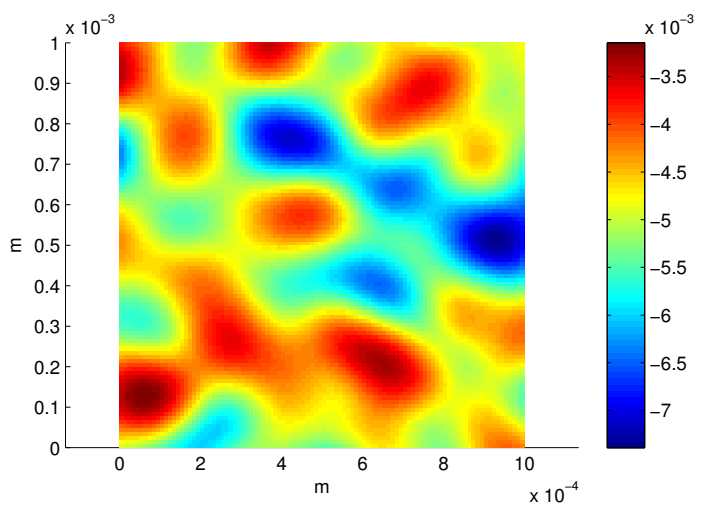

Fig. 3 Component $\left\{\varepsilon_{\exp }^{\text {meso }}\right\}_{22}$ of the simulated experimental strain field at mesoscale with a resolution $100 \times 100$

value of $\mathbf{a}=\left(E_{T}^{\text {macro }}, v_{T}^{\text {macro }}\right)$ is $\mathbf{a}^{\text {macro }}=\left(9.565 \times 10^{9} \mathrm{~Pa}, 0.3987\right)$.

Table 1 shows the values of $\mathbf{b}=\left(\ell, \delta, E_{T}, v_{T}\right)$ for each point of the Pareto front displayed in Fig. 4. The optimal values correspond to the points 5, 6, 7, 8 and 9 where points 6 et 7 are close. The optimal value $\mathbf{b}^{\text {meso }}$ is such that $\ell^{\text {meso }}=9.66 \times$ $10^{-5} \mathrm{~m}, \delta^{\text {meso }}=0.37, E_{T}^{\text {meso }}=1.023 \times 10^{10} P a, v_{T}^{\text {meso }}=0.376$. This result yields a validation of the proposed methodology since this identified optimal value $\mathbf{b}^{\text {meso }}$ is 
very close to the value $\mathbf{b}$ that has been used to construct the simulated experimental database and for which $\ell=1.25 \times 10^{-4} \mathrm{~m}, \delta=0.4, E_{T}=9.9 \times 10^{9} \mathrm{~Pa}, v_{T}=0.38$.

Table 1 Optimization in using the genetic algorithm

\begin{tabular}{ccccccc}
\hline $\mathrm{k}$ & $\mathscr{I}_{2}(\mathbf{b})$ & $\mathscr{I}_{3}(\mathbf{a}, \mathbf{b})$ & $\ell$ & $\delta$ & $E_{T}$ & $v_{T}$ \\
\hline 1 & $5.006529 \times 10^{-9}$ & $2.311672 \mathrm{e}-01 \times 10^{-1}$ & $1.886667 \times 10^{-4}$ & 0.400000 & $1.023000 \times 10^{10}$ & 0.392667 \\
2 & $5.006529 \times 10^{-9}$ & $9.477024 \times 10^{-2}$ & $2.500000 \times 10^{-4}$ & 0.400000 & $1.023000 \times 10^{10}$ & 0.392667 \\
3 & $5.010827 \times 10^{-9}$ & $9.469903 \times 10^{-2}$ & $9.666667 \times 10^{-5}$ & 0.366667 & $1.023000 \times 10^{10}$ & 0.376200 \\
4 & $5.132208 \times 10^{-9}$ & $9.201960 \times 10^{-2}$ & $1.273333 \times 10^{-4}$ & 0.383333 & $1.023000 \times 10^{10}$ & 0.392667 \\
5 & $5.240100 \times 10^{-9}$ & $3.467300 \times 10^{-2}$ & $9.666667 \times 10^{-5}$ & 0.366667 & $1.023000 \times 10^{10}$ & 0.359733 \\
6 & $5.259407 \times 10^{-9}$ & $2.455275 \times 10^{-2}$ & $5.066667 \times 10^{-5}$ & 0.350000 & $8.943000 \times 10^{9}$ & 0.293867 \\
7 & $5.259407 \times 10^{-9}$ & $2.455275 \times 10^{-2}$ & $9.666667 \times 10^{-5}$ & 0.366667 & $1.023000 \times 10^{10}$ & 0.376200 \\
8 & $5.386876 \times 10^{-9}$ & $2.064010 \times 10^{-2}$ & $5.066667 \times 10^{-5}$ & 0.350000 & $8.943000 \times 10^{9}$ & 0.310333 \\
9 & $5.490529 \times 10^{-9}$ & $1.968774 \times 10^{-2}$ & $5.066667 \times 10^{-5}$ & 0.350000 & $1.237500 \times 10^{10}$ & 0.293867 \\
10 & $6.57386 \times 10^{-9}$ & $1.962839 \times 10^{-2}$ & $2.193333 \times 10^{-4}$ & 0.400000 & $1.023000 \times 10^{10}$ & 0.392667 \\
11 & $6.895467 \times 10^{-9}$ & $1.885624 \times 10^{-2}$ & $2.500000 \times 10^{-4}$ & 0.383333 & $1.023000 \times 10^{10}$ & 0.392667 \\
12 & $7.254986 \times 10^{-9}$ & $1.759584 \times 10^{-2}$ & $2.500000 \times 10^{-4}$ & 0.333333 & $1.023000 \times 10^{10}$ & 0.392667 \\
13 & $7.567184 \times 10^{-9}$ & $1.688894 \times 10^{-2}$ & $9.666667 \times 10^{-5}$ & 0.383333 & $1.023000 \times 10^{10}$ & 0.392667 \\
14 & $7.996816 \times 10^{-9}$ & $1.623193 \times 10^{-2}$ & $2.000000 \times 10^{-5}$ & 0.350000 & $8.943000 \times 10^{9}$ & 0.310333 \\
15 & $9.129340 \times 10^{-9}$ & $1.507042 \times 10^{-2}$ & $2.500000 \times 10^{-4}$ & 0.366667 & $1.023000 \times 10^{10}$ & 0.392667 \\
16 & $9.368447 \times 10^{-9}$ & $1.333442 \times 10^{-2}$ & $1.273333 \times 10^{-4}$ & 0.266667 & $1.023000 \times 10^{10}$ & 0.392667 \\
\hline
\end{tabular}

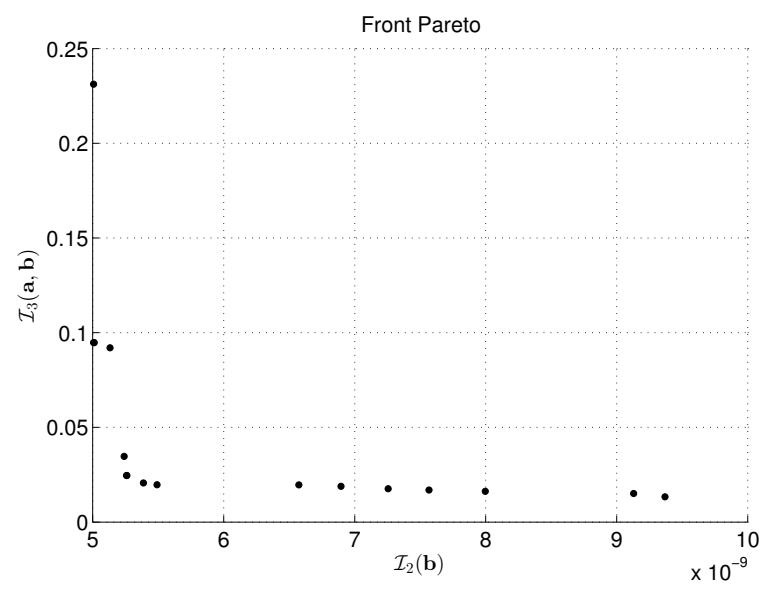

Fig. 4 Pareto front for the numerical indicators $\mathscr{I}_{2}(\mathbf{b})$ et $\mathscr{I}_{3}(\mathbf{a}, \mathbf{b})$ 


\section{Conclusions}

A multiscale inverse statistical method has been presented for the identification, in the framework of the 3D linear elasticity and in using experimental measurements at macroscale and at mesoscale, of the stochastic model of the apparent elasticity random field at mesoscale for a heterogeneous microstructure. A prior stochastic model depending of vector-valued parameter has been proposed for the apparent elasticity random field at mesoscale in the case of $2 \mathrm{D}$ plane stress. The identification has been formulated as the a multi-objective minimization problem with respect to the parameter of the prior stochastic model. The optimal value of the of the parameter corresponds to the point that minimizes the distance of a Pareto front to the origin. The proposed statistical inverse method has been validated with a simulated experimental database.

Acknowledgements This research was supported by the "Agence Nationale de la Recherche", Contract TYCHE, ANR-2010-BLAN-0904.

\section{References}

1. Arnst, M., Clouteau, D., Bonnet, M.: Inversion of probabilistic structural models using measured transfer functions. Computer Methods in Applied Mechanics and Engineering 197, 589-608 (2008)

2. Avril, S., Bonnet, M., Bretelle, A.S., Grédiac, M., Hild, F., Ienny, P., Latourte, F., Lemosse, D., Pagano, S., Pagnacco, E., Pierron, F.: Overview of identification methods of mechanical parameters based on full-field measurements. Experimental Mechanics 48, 381-402 (2008)

3. Avril, S., Pierron, F.: General framework for the identification of constitutive parameters from full-field measurements in linear elasticity. International Journal of Solids and Structures 44, 4978-5002 (2007)

4. Avril, S., Pierron, F., Pannier, Y., Rotinat, R.: Stress reconstruction and constitutive parameter identification in plane-stress elastoplastic problems using surface measurements of deformation fields. Experimental Mechanics pp. 403-419 (2008)

5. Babuska, I., Nobile, F., Tempone, R.: A stochastic collocation method for elliptic partial differential equations with random input data. SIAM J. Numer. Anal. 45 (3), 1005-1034 (2007)

6. Babuska, I., Tempone, R., Zouraris, G.E.: Solving elliptic boundary value problems with uncertain coefficients by the finite element method: the stochastic formulation. Comput. Methods Appl. Mech. Engrg. 194 (12-16), 1251-1294 (2005)

7. Baxter, S.C., Graham, L.L.: Characterization of random composites using a moving window technique. ASCE J Engng Mech 126(4), 389-404 (2000)

8. Besnard, G., Hild, F., Roux, S.: Finite-element displacement fields analysis from digital images: Application to portevin-le chatelier bands. Experimental Mechanics 46, 789-803 (2006)

9. Bonnet, M., Constantinescu, A.: Inverse problems in elasticity. Inverse Probl 21, R1-R50 (2005)

10. Bornert, M., Brémand, F., Doumalin, P., Dupré, J.C., Fazzini, M., Grédiac, M., Hild, F., Mistou, S., Molimard, J., Orteu, J.J., Robert, L., Surrel, Y., Vacher, P., Wattrisse, B.: Assessment of digital image correlation measurement errors: Methodology and results. Experimental Mechanics 49, 353-370 (2009) 
11. Bornert, M., Vales, F., Gharbi, H., Nguyen Minh, D.: Multiscale full-field strain measurements for micromechanical investigations of the hydromechanical behaviour of clayey rocks. Strain 46, 33-46 (2010)

12. Calloch, S., Dureisseix, D., Hild, F.: Identification de modèles de comportement de matériaux solides: utilisation d'essais et de calculs. Technol Form 100, 36-41 (2002)

13. Chevalier, L., Calloch, S., Hild, F., Marco, Y.: Digital image correlation used to analyze the multiaxial behavior of rubber-like materials. European Journal of Mechanics A-Solids 20, 169-187 (2001)

14. Clouteau, D., Cottereau, R., Lombaert, G.: Dynamics of structures coupled with elastic media - a review of numerical models and methods. Journal of Sound and Vibration 332, 2415-2436 (2013)

15. Collins, J.C., Hart, G.C., Kennedy, B.: Statistical identification of structures. AIAA J 12, 185-190 (1974)

16. Constantinescu, A.: On the identification of elastic moduli from displacement-force boundary measurements. Inverse Probl Eng 1, 293-315 (1995)

17. Das, S., Ghanem, R., Finette, S.: Polynomial chaos representation of spatiotemporal random field from experimental measurements. J. Comput. Phys. 228, 8726-8751 (2009)

18. Das, S., Ghanem, R., Spall, J.: Asymptotic sampling distribution for polynomial chaos representation of data: a maximum-entropy and fisher information approach. SIAM J. Sci. Comput. 30 (5), 2207-2234 (2008)

19. Desceliers, C., Ghanem, R., Soize, C.: Maximum likelihood estimation of stochastic chaos representations from experimental data. International Journal For Numerical Methods In Engineering 66, 978-1001 (2006)

20. Desceliers, C., Soize, C., Ghanem, R.: Identification of chaos representations of elastic properties of random media using experimental vibration tests. Comput.Mech. 39(6), 831-838 (2007)

21. Desceliers, C., Soize, C., Naili, S., Haiat, G.: Probabilistic model of the human cortical bone with mechanical alterations in ultrasonic range. Mechanical Systems and Signal Processing 32, 170-177 (2012)

22. Geymonat, G., Hild, F., Pagano, S.: Identification of elastic parameters by displacement field measurement. Comptes Rendus Mécanique 330, 403-408 (2002)

23. Geymonat, G., Pagano, S.: Identification of mechanical properties by displacement field measurement: a variational approach. Meccanica 38, 535-545 (2003)

24. Graham, L.L., Gurley, K., Masters, F.: Non-gaussian simulation of local material properties based on a moving-window technique. Prob. Eng. Mechanics 18, 223-234 (2003)

25. Guilleminot, J., Soize, C.: Non-gaussian positive-definite matrix-valued random fields with constrained eigenvalues: Application to random elasticity tensors with uncertain material symmetries. International Journal for Numerical Methods in Engineering 88, 1128-1151 (2011)

26. Guilleminot, J., Soize, C.: Generalized stochastic approach for constitutive equation in linear elasticity: a random matrix model. International Journal for Numerical Methods in Engineering 90, 613-635 (2012)

27. Guilleminot, J., Soize, C.: Probabilistic modeling of apparent tensors in elastostatics: A maxent approach under material symmetry and stochastic boundedness constraints. Probabilistic Engineering Mechanics 28, 118-124 (2012)

28. Guilleminot, J., Soize, C.: On the statistical dependence for the components of random elasticity tensors exhibiting material symmetry properties. Journal of Elasticity 111, 109-130 (2013)

29. Guilleminot, J., Soize, C., Kondo, D.: Mesoscale probabilistic models for the elasticity tensor of fiber reinforced composites: Experimental identification and numerical aspects. Mechanics of Materials 41, 1309-1322 (2009)

30. Hild, F.: CORRELI ${ }^{L M T}$ : a software for displacement field measurements by digital image correlation. LMT-Cachan, internal report 254 (2002)

31. Hild, F., Périé, J.N., Coret, M.: Mesure de champs de déplacements 2D par intercorrélation d'images: CORRELI 2D. LMT-Cachan, internal report 230 (1999) 
32. Hild, F., Raka, B., Baudequin, M., Roux, S., Cantelaube, F.: Multiscale displacement field measurements of compressed mineral-wool samples by digital image correlation. Applied Optics 41, 6815-6828 (2002)

33. Hild, F., Roux, S.: Digital image correlation: from displacement measurement to identification of elastic properties - a review. Strain 42, 69-80 (2006)

34. Hild, F., Roux, S.: Comparison of local and global approaches to digital image correlation. Experimental Mechanics 52, 1503-1519 (2012)

35. Jeulin, D.: Microstructure modeling by random textures. Journal de Microscopie et de Spectroscopie Electroniques 12, 133140 (1987)

36. Jeulin, D.: Morphological modeling of images by sequential random functions. Signal Processing 16, 403431 (1989)

37. Jeulin, D.: Caractérisation morphologique et modèles de structures aléatoires. In Homogénéisation en mécanique des matériaux 1. Hermès Science Publications (2001)

38. Kaipio, J., Somersalo, E.: Statistical and Computational Inverse Problems. Springer-Verlag, New York (2005)

39. Lawson, C.L., Hanson, R.J.: Solving Least Squares Problems. Prentice-Hall (1974)

40. Madi, K., Forest, S., Boussuge, M., Gailliegue, S., Lataste, E., Buffiere, J.Y., Bernard, D., Jeulin, D.: Finite element simulations of the deformation of fused-cast refractories based on x-ray computed tomography. Computational Materials Science 39, 224-229 (2007)

41. Rethore, J., Tinnes, J.P., Roux, S., Buffiere, J.Y., Hild, F.: Extended three-dimensional digital image correlation (X3D-DIC). Comptes Rendus Mécanique 336, 643-649 (2008)

42. Roux, S., Hild, F.: Digital image mechanical identification (DIMI). Experimental Mechanics 48, 495-508 (2008)

43. Roux, S., Hild, F., Berthaud, Y.: Correlation image velocimetry: a spectral approach. Applied Optics 41, 108-115 (2002)

44. Roux, S., Hild, F., Viot, P., Bernard, D.: Three-dimensional image correlation from X-ray computed tomography of solid foam. Composites Part A-Applied Science and Manufacturing 39, 1253-1265 (2008)

45. Serfling, R.J.: Approximation Theorems of Mathematical Statistics. John Wiley and Sons (1980)

46. Soize, C.: Non-gaussian positive-definite matrix-valued random fields for elliptic stochastic partial differential operators. Computer Methods in Applied Mechanics and Engineering 195, 26-64 (2006)

47. Soize, C.: Tensor-valued random fields for meso-scale stochastic model of anisotropic elastic microstructure and probabilistic analysis of representative volume element size. Probabilistic Engineering Mechanics 23, 307-323 (2008)

48. Soize, C.: Identification of high-dimension polynomial chaos expansions with random coefficients for non-gaussian tensor-valued random fields using partial and limited experimental data. Computer Methods in Applied Mechanics and Engineering 199, 2150-2164 (2010)

49. Soize, C.: Stochastic Models of Uncertainties in Computational mechanics, Lecture Notes in Mechanics, vol. 2. American Society of Civil Engineers, Reston (2012)

50. Spall, J.C.: Introduction to Stochastic Search and Optimization. John Wiley and Sons, Hoboken, New Jersey (2003)

51. Ta, Q.A., Clouteau, D., Cottereau, R.: Modeling of random anisotropic elastic media and impact on wave propagation. European Journal of Computational Mechanics 19, 241-253 (2010)

52. Walter, E., Pronzato, L.: Identification of Parametric Models from Experimental Data. Springer (1997) 